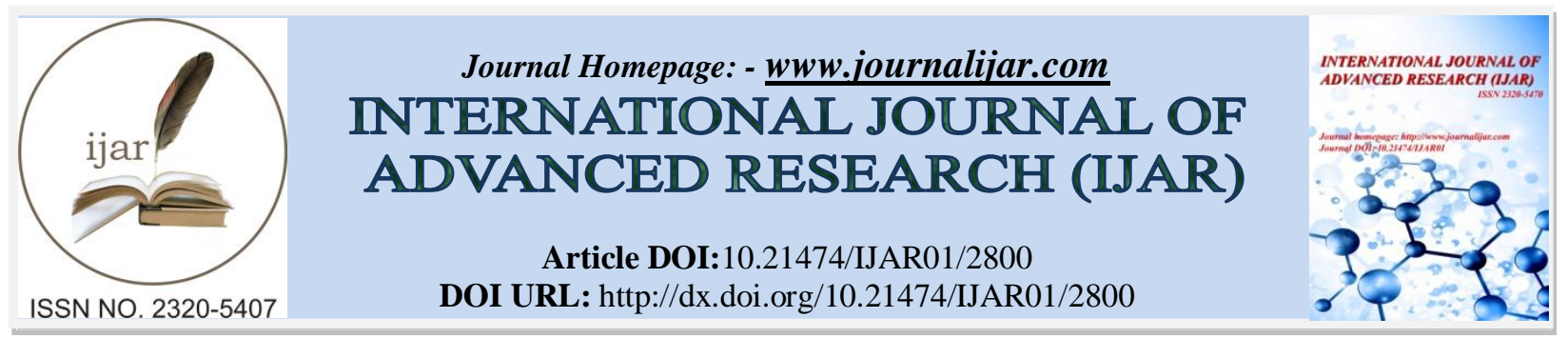

RESEARCH ARTICLE

\title{
THE IMPACT OF BOXING EXPERIENCE ON SHOULDER INTERNAL ROTATOR MUSCLES CONCENTRIC AND ECCENTRIC STRENGTH.
}

\section{Ioannis Tasiopoulos ${ }^{1}$, Alexandra Tripolitsioti ${ }^{2}$, Pantelis Nikolaidis ${ }^{3}$ and Apostolos Stergioulas ${ }^{4}$.}

1. MS, PhDc Faculty of Human Movement \& Quality of Life, Peloponnese University, Efstathiou \& Stamatikis Balioti \& Plateon, 23100, Sparta, Laconia, Greece.

2. Special staff, Faculty of Human Movement \& Quality of Life, Peloponnese University, Efstathiou \& Stamatikis Balioti \& Plateon, 23100, Sparta, Laconia, Greece.

3. Professor, Director Lab of Health, Fitness and Disability Management, Faculty of Human Movement \& Quality of Life, Peloponnese University, Efstathiou \& Stamatikis Balioti \& Plateon, 23100, Sparta, Laconia, Greece.

4. Exercise Physiology Laboratory,Thermopilon 7, 18450, Nikaia, Athens, Greece.

\section{Manuscript Info}

Manuscript History

Received: 15 November 2016

Final Accepted: 17 December 2016

Published: January 2017

Key words:-

Amateur boxing, shoulder torque,

internal /external rotation

\section{Abstract}

The aim of the study was to determine the impact of boxing experience on shoulder internal rotators concentric and eccentric strength of amateur male boxers. Forty amateur boxing athletes participated voluntary in the study. Measurements of internal rotators concentric and eccentric strength of both shoulders were done under static conditions on a Kin-ComTM (Chattecx, Chattanooga, TN) dynamometer at angular velocities of 60,120 and $180^{\circ} / \mathrm{sec}$. One way analysis of data revealed the following significant differences: At $60^{\circ} / \mathrm{sec}$ : Between boxing experience and shoulder internal rotators concentric and eccentric strength both in dominant arm $(p<0.001 \&$ $\mathrm{p}<0.03$ respectively) and in non-dominant arm $(p<0.03 \& p<0.04)$. At $120^{\circ} \mathrm{sec}$ : Between boxing experience and shoulder internal rotators concentric and eccentric strength of the dominant arm $(p<0.001$ and $p<0.005)$. At $180^{\circ} / \mathrm{sec}$ : Between boxing experience and shoulder internal concentric and eccentric contraction in dominant arm $(p<0.016$ and $p<0.019)$. Post hoc corrections with bonferroni method revealed: At $60^{\circ} / \mathrm{sec}$ : Boxers who had experience more than $10 \mathrm{y}$ had greater shoulder internal rotators concentric and eccentric strength in dominant hand, in relation to athletes with experience $5 \mathrm{y}(p<0.002$ and $p<0.04$ ). Boxers who had experience more than $10 \mathrm{y}$ had greater shoulder internal rotators concentric and eccentric strength in nondominant arm, in relation to the athletes with experience $5 \mathrm{y}(p<0.002$ and $\mathrm{p}<0.005)$.At $120^{\circ} / \mathrm{sec}$ : Boxers who had experience more than $10 \mathrm{y}$ had greater shoulder internal rotators concentric and eccentric strength in dominant hand, in relation with the athletes with experience $5 \mathrm{y}$ $(p<0.001$ and $\mathrm{p}<0.05)$.At $180^{\circ} / \mathrm{sec}$ : Boxers who had experience more than $10 \mathrm{y}$ had greater shoulder internal rotators concentric and eccentric strength in dominant hand, in relation with the athletes with experience $5 \mathrm{y}(p<0.017)$. It is concluded that the boxing experience has positive effects on shoulder internal rotators concentric and eccentric strength of amateur male boxers. 


\section{Introduction:-}

Boxing is one between combat sports that demands both physical and mental characteristics. As with other sports the participation in the boxing requires agility optimal coordination, endurance, speed, strength and stamina (Koutedakis and Jamurtas, 2004; Chaabène, et al, 2014). The number of rounds is the main difference that characterized the amateur boxing to the professional one. However participation in both, the scope of the boxers is to earn points and to win the round by delivering clear punches to opponent's target areas, using different tactics and strategies. The three types of the boxing punches are, a) the straight, b) the hook and c) the uppercut.

It is known that supraspinatus, infraspinatus, teres minor and subscapularis are the muscles group that comprise the rotator cuff of the shoulder joint.

These muscles are grouped together because they have rotational functions of the humerus and because their tendon interwoven into the capsule to form the musculotendinous cuff around the joint. They act together to hold the head of the humerus bone against the glenoid fossa and thus to stabilize the shoulder joint against downward dislocation of the mentioned bone. These muscles are activated with the help of deltoid muscle during abduction and flexion of the shoulder joint. The power line of these muscles contributes to the dynamic stability of the joint. The infraspinatus, teres minor and subscapularis when acting generate a force that moves the humerus downwards (Stergioulas and Aggelidis, 2001).Thus, this force reduces the shearing stress between the head and glenoid, which is higher at 45 degrees abduction.

The infraspinatus and teres minor except for the stabilizing role contribute to the movement of abduction external rotation causing the humerus, which does not allow the impact on major humeral tuberosity at the acromion process. The deltoid contraction causes displacement of humerus upwards and the contraction the muscles infraspinatus, teres minor and subscapularis creates a force couple. In the power pair, the traction forces cause pure rotation movement, in this case the head of the humerus rotating around a fixed axis of rotation, (Stergioulas and Aggelidis, 2001; Stergioulas, 2005).Thus, the humeral head is stabilized in the glenoid fossa and the supraspinatus with the deltoid can lift the upper extremity during the abduction (Stergioulas, 1991).

As by the above analysis one can be understood, the shoulder internal rotators are involved in the initial segments of the straight and hook punches, while with the uppercut the external ones. External and internal shoulder rotators muscles maintain glenohumeral joint, stabilize the rotator cuff and promote the integrity throughout the range of movements, that included in the hook, uppercut and straight punches (Pędzich et al., 2012).

The isokinetic dynamometer is an accepted modality used to assess functional parameters of antagonist/agonist muscles involved in different physical activities (Ellenbecker \& Davies, 2000; Koutedakis et al., 1998). However, we found no published data on shoulder rotator muscle dynamometer characteristics in relation to amateur boxing. So, in the current literature there is a lack of knowledge regarding the impact of boxing experience in power of concentric/eccentric internal rotations muscle of the shoulder in the amateur boxing sportsmen in different speeds.

Therefore, to bridge this literature the purpose of the present study was to confirm if the boxing experience has anyimpact on shoulder internal rotation concentric and eccentric strength of amateur boxer athletes at the angular velocities of 60,120 and $180^{\circ} / \mathrm{sec}$.

\section{Materials and Method:-}

\section{Samples:-}

Volunteers for this investigation $(n=40)$ were uninjured members of amateur Greek boxing clubs, recruited from a larger study sample. To be eligible for participation in the investigation, the amateur boxers were required to have competed the 5 consecutive years before the study primarily as a boxer in organized amateur boxing matches in any category, to be uninjured and unrestricted in boxing activities at the time of testing. All participants were informed on the purpose of the study and signed the agreement forms before tests. That study was approved by the Ethic Committee of the University Peloponnese Review Board in January 2015. 


\section{Measurements:-}

The Kin-ComTM (Chattecx, Chattanooga, TN) dynamometer was used for the determination of the peak torque of the internal/external rotators of both shoulders, during concentric and eccentric contractions at the angular velocities of 60,120 and $180^{\circ} / \mathrm{sec}$.

After the general warm-up exercises, male amateur boxers informed on the Kin-com apparatus system. The sitting position in 45 degrees of shoulder abduction in scapular plane, gives more anatomical advantages without any rate difference with upright in 90 degrees of shoulder abduction and frontal plane, (Hellwig, \& Perrin., 1991), while it seems to be the most reliable power evaluation positions for internal and external rotation (Eduard et al., 2011). The device tilted to up 45 degrees (to allow 45 degrees of abduction of the shoulder) and adjusted to the lowest available rate. The joint rotation axis aligned with the axis of the arm by changing the height of the seat. The best alignment determined by visual inspection, the frontal and scapular position and seat height adjusted for each subject. The lower ends of each testing subject, supported in a chair throughout the test procedure.

The trunk and hips stabilized during the warm-up and testing repetitions. The stabilization of the trunk became with a belt that is positioned horizontally across the chest and is secured to the back of the chair and the stabilization of the hip provided with a belt positioned about 45 degrees across the pelvis and is secured to the chair. The movable seat stabilized at the position where finds the best test position.

The elbow placed in 90 degrees of flexion. The elbow/shoulder supported by the use of belt. The length of the lever arm was inserted into the computer. The peak torque of the internal/external rotators of the shoulders, during concentric contractions were measured at the angular velocities of 60,120 and $180 \%$ sec for all subjects.

Before the maximum effort measurements, warm up contractions were executed, consisted of three sub maximal repetitions and two maximal ones, both concentric and eccentric contractions in accordance with the test protocol (continuous or intermittent). After this procedure two minutes break in the warm-up and test followed.

The evaluation processes consisted of three repetitions of maximal voluntary eccentric and concentric contraction at internal and external rotation at the angular velocities of $60 \% \mathrm{sec}$ and $180 \% \mathrm{sec}$. Each maximal concentric contraction was measured first, followed by an eccentric contraction. There was a two-minute rest between tests of two muscle groups. Any subject tested first in rotation at the angular velocities of $60^{\circ} / \mathrm{sec}$ and $180^{\circ} / \mathrm{sec}$ (Wilhite et al., 1992). A 2-minute rest was between the two angular velocities. During the maximum contraction test, the subjects were not allowed to use the other upper extremity of stabilization. The range of motion during the tests of the internal rotation was from $90^{\circ}$ to $0^{\circ}$ and from $0^{\circ}$ to $90^{\circ}$ for the external rotation.

The intermittent contraction protocol allowed $5 \mathrm{sec}$ break sin concentric and eccentric contraction. Verbal encouragement is not used during the warm-up period or during the test. All measurements were conducted in the Skordis rehabilitation center (http: www.skordis.gr)

\section{Statistics:-}

The data were statistically analyzed by statistical package for social sciences program (version 21.0). Analysis of variance (ANOVA) and post hoc Bonferroni method was used to compare the experience years with of the peak torque of the internal rotators of the dominant hand, during concentric/eccentric contraction. The level of significance was set at $\mathrm{p}=0.05$ probability level.

\section{Results:-}

The age of the subjects was $25.48 \pm 3.49 \mathrm{y}$, the height $1.77 \pm 6.01 \mathrm{~cm}$ and body weight $78.80 \pm 8.76 \mathrm{~kg}$. Nine athletes had 0-5 y experience, 17 athletes had 6-10 y experience and 14 of athletes had up to 10 y experience.

In the table 1 are presented the statistics of the internal concentric and eccentric contraction of the shoulder muscles according to boxing experience (One way ANOVA).

\section{At angular velocity of $60 \%$ sec:-}

There was a significant difference between boxing experience and shoulder internal rotators concentric strength in dominant arm $\left(\mathrm{F}_{2,37}=7.55, p<0.002\right)$. Further correction by Bonferroni method showed that boxers who had 
experience more than 10 y $(57.36 \pm 4.62 \mathrm{~N})$, had greater shoulder internal rotators concentric strength in dominant arm, in relation to athletes with experience 5 y $(50.33 \pm 2.45 \mathrm{~N}, p<0.002)$.

There was a significant difference between boxing experience and shoulder internal rotators concentric strength in non-dominant arm $\left(\mathrm{F}_{2,37}=3.72, p<0.034\right)$.

Further correction by Bonferroni method showed that boxers who had experience more than $10 \mathrm{y}(51.85 \pm 3.79 \mathrm{~N})$, had greater shoulder internal rotators concentric strength in non-dominant arm, in relation to athletes with experience 5 y $(48.66 \pm 4.36)$.

There was a significant difference between boxing experience and shoulder internal rotators eccentric strength in dominant arm $\left(\mathrm{F}_{2,37}=4.034, p<0.026\right)$. Further correction by Bonferroni method showed that boxers who had experience more than $10 \mathrm{y}(69.21 \pm 8.70 \mathrm{~N})$ had greater shoulder internal rotators eccentric strength in dominant arm, in relation to athletes with experience 5 y $(59.67 \pm 10.19 \mathrm{~N}, p<0.05)$.

There was a significant difference between boxing experience and shoulder internal rotators eccentric strength in non-dominant arm $\left(\mathrm{F}_{2,37}=3.39, p<0.044\right)$. Further correction by Bonferroni method showed that boxers who had experience more than $10 \mathrm{y}(62.29 \pm 4.53 \mathrm{~N})$, had greater shoulder internal rotators eccentric strength in non-dominant arm, in relation to athletes with experience 5 y $(56.22 \pm 8.08 \mathrm{~N}, p<0.05)$.

At angular velocity of $120^{\circ} / \mathrm{sec}$ :(i) There was a significant difference between boxing experience and shoulder internal rotators concentric strength in dominant arm $\left(\mathrm{F}_{2,37}=12.73, p<0.001\right)$. Further correction by Bonferroni method showed that boxers who had experience more than $10 \mathrm{y}(51.50 \pm 5.85 \mathrm{~N})$, had greater shoulder internal rotators concentric strength in dominant arm, in relation to athletes with experience $5 \mathrm{y}(43.56 \pm 1.94 \mathrm{~N}, p<0.002)$.

There was a significant difference between boxing experience and shoulder internal rotators eccentric strength in dominant arm $\left(\mathrm{F}_{2,37}=4.00, p<0.05\right)$. Further correction by Bonferroni method showed that boxers who had experience more than $10 \mathrm{y}(63.93 \pm 9.09 \mathrm{~N})$, had greater shoulder internal rotators concentric strength in dominant arm, in relation to athletes with experience 5 y $(54.00 \pm 9.34 \mathrm{~N}, p<0.05)$.

At angular velocity of $180^{\circ} / \mathrm{sec}$ : (i) There was a significant difference between boxing experience and shoulder internal rotators concentric strength in dominant $\operatorname{arm}\left(\mathrm{F}_{2,37}=4.66, p<0.016\right)$. Further correction by Bonferroni method showed that boxers who had experience more than $10 \mathrm{y}(45.57 \pm 5.58 \mathrm{~N})$, had greater shoulder internal rotators concentric strength in dominant arm, in relation to athletes with experience 5 y $(39.00 \pm 4.35 \mathrm{~N}, p<0.017)$.

There was a significant difference between boxing experience and shoulder internal rotators eccentric strength in dominant arm $\left(\mathrm{F}_{2,37}=6.77, p<0.019\right)$. Further correction by Bonferroni method showed that boxers who had experience more than $10 \mathrm{y}(60.50 \pm 6.69 \mathrm{~N})$, had greater shoulder internal rotators eccentric strength in dominant arm, in relation to athletes with experience 5 y $(50.00 \pm 6.77 \mathrm{~N}, p<0.035)$.

Table 1: - Comparison between mean values of IRcon and IRecc at $60,120,180 \% \mathrm{sec}$ of boxers and years of experience (Analysis of variance).

\begin{tabular}{|c|c|c|c|c|c|c|}
\hline & & Sum of Squares & $\mathrm{df}$ & Mean Square & $\mathrm{F}$ & Sig. \\
\hline \multirow[t]{3}{*}{ IRcon60D $^{1}$} & Between Groups & 282.92 & 2 & 141.46 & 7.54 & .002 \\
\hline & Within Groups & 693.45 & 37 & 18.74 & & \\
\hline & Total & 976.37 & 39 & & & \\
\hline \multirow[t]{3}{*}{ IRcon60ND $^{2}$} & Between Groups & 98.02 & 2 & 49.01 & 3.72 & .034 \\
\hline & Within Groups & 487.95 & 37 & 13.188 & & \\
\hline & Total & 585.97 & 39 & & & \\
\hline \multirow[t]{3}{*}{ IRecc60D $^{3}$} & Between Groups & 522.02 & 2 & 261.00 & 4.03 & .026 \\
\hline & Within Groups & 2394.36 & 37 & 64.71 & & \\
\hline & Total & 2916.37 & 39 & & & \\
\hline \multirow[t]{3}{*}{$\mathrm{IRecc} 60 \mathrm{ND}^{4}$} & Between Groups & 217.08 & 2 & 108.54 & 3.40 & .044 \\
\hline & Within Groups & 1184.29 & 37 & 32.00 & & \\
\hline & Total & 1401.37 & 39 & & & \\
\hline IRcon120D $^{5}$ & Between Groups & 416.25 & 2 & 208.12 & 12.72 & .000 \\
\hline
\end{tabular}




\begin{tabular}{|c|c|c|c|c|c|c|}
\hline & Within Groups & 605.25 & 37 & 16.36 & & \\
\hline & Total & 1021.50 & 39 & & & \\
\hline \multirow[t]{3}{*}{${\text { IRcon } 120 N^{6}}^{6}$} & Between Groups & 85.34 & 2 & 42.67 & 2.04 & .145 \\
\hline & Within Groups & 774.56 & 37 & 20.93 & & \\
\hline & Total & 859.90 & 39 & & & \\
\hline \multirow[t]{3}{*}{ IRecc120D $^{7}$} & Between Groups & 545.11 & 2 & 272.56 & 4.00 & .050 \\
\hline & Within Groups & 2523.99 & 37 & 68.22 & & \\
\hline & Total & 3069.10 & 39 & & & \\
\hline \multirow[t]{3}{*}{ IRecc120ND $^{8}$} & Between Groups & 197.80 & 2 & 98.90 & 2.30 & .115 \\
\hline & Within Groups & 1593.80 & 37 & 43.08 & & \\
\hline & Total & 1791.60 & 39 & & & \\
\hline \multirow[t]{3}{*}{ IRcon180D ${ }^{9}$} & Between Groups & 254.47 & 2 & 127.23 & 4.66 & .016 \\
\hline & Within Groups & 1009.31 & 37 & 27.28 & & \\
\hline & Total & 1263.77 & 39 & & & \\
\hline \multirow[t]{3}{*}{ IRcon $180 \mathrm{ND}^{10}$} & Between Groups & 34.68 & 2 & 17.34 & .884 & .422 \\
\hline & Within Groups & 726.09 & 37 & 19.62 & & \\
\hline & Total & 760.77 & 39 & & & \\
\hline \multirow[t]{3}{*}{ IRecc180D $^{11}$} & Between Groups & 646.24 & 2 & 323.12 & 6.77 & .019 \\
\hline & Within Groups & 1765.74 & 37 & 47.72 & & \\
\hline & Total & 2411.98 & 39 & & & \\
\hline \multirow[t]{3}{*}{ IRecc180ND $^{12}$} & Between Groups & 171.88 & 2 & 85.94 & 2.63 & .297 \\
\hline & Within Groups & 1209.90 & 37 & 32.70 & & \\
\hline & Total & 1381.78 & 39 & & & \\
\hline
\end{tabular}

1. IRcon $60 \mathrm{D}=$ Concentric contraction at $60^{\circ} / \mathrm{sec}$ of dominant hand

2. IRcon $60 \mathrm{ND}=$ Concentric contraction at $60 \% \mathrm{sec}$ of non-dominant hand

3. IRecc $60 \mathrm{D}=$ Eccentric contraction at $60 \% \mathrm{sec}$ of dominant hand

4. IRecc60ND $=$ Eccentric contraction at $60 \% \mathrm{sec}$ of non-dominant hand

5. IRcon $120 \mathrm{D}=$ Concentric contraction at $120 \% \mathrm{sec}$ of dominant hand

6. IRcon $120 \mathrm{ND}=$ Concentric contraction at $120 \% \mathrm{sec}$ of non-dominant hand

7. IRecc $120 \mathrm{D}=$ Eccentric contraction at $120 \% \mathrm{sec}$ of dominant hand

8. IRecc $120 \mathrm{ND}=$ Eccentric contraction at $120 \% \mathrm{sec}$ of non-dominant hand

9. IRcon $180 \mathrm{D}=$ Concentric contraction at $180 \% \mathrm{sec}$ of dominant hand

10. IRcon $180 \mathrm{ND}=$ Concentric contraction at $180 \% \mathrm{sec}$ of non-dominant hand

11. IRecc $180 \mathrm{D}=$ Eccentric contraction at $180 \% \mathrm{sec}$ of dominant hand

12. IRecc $180 \mathrm{ND}=$ Eccentric contraction at $180 \% \mathrm{sec}$ of non-dominant hand

\section{Discussion:-}

We conducted the present investigation to confirm if the boxing experience has any impact on shoulder internal concentric/eccentric strength of amateur boxing athletes.

Although in several sports in which the athletes using the hand above the horizontal plane have been conducted many studies, the present investigation is the first, that determined the effects of training experience of shoulder internal concentric/eccentric strength in amateur boxers.

We hypothesized initially that concentric and eccentric internal rotators strength at angular velocity of $60^{\circ} / \mathrm{sec}$ could be increased bilateral and symmetrical over the years of training and competitive boxing. Our results confirmed this hypothesis, since we found differences between boxers who had experience 0 to $5 \mathrm{y}$ and those with up to $10 \mathrm{y}$, in concentric and eccentric internal rotation strength in both shoulders (dominant and non-dominant arm).

It seems that the internal rotators act concentrically during the acceleration phase of the boxing punches such as the hook, straight and uppercut. This loads, which occurs in training activities and fighting increases the biomechanical adaptations of muscle tendon units of internal rotators. These adaptations of the subscapularis and inner deltoid, improved because of neuromuscular adaptations of the number and the type motor units that are recruited and activated, the frequency of each pulse of the motor unit, the size of the muscle fibers, the sarcomere length and the speed of contraction. More, the effect of neuromuscular training in the boxing punches and the participation in non- 
dominant hand during these synergies, increase the internal rotators power simultaneously (Andrade et al., 2010; Bompa and Buzzichelli, 2015).

Other researchers confirmed that sport specific training with regular, repeated throwing motions causes an increase in the shoulder internal rotator muscle torques in the dominant arm, thus contributed to glenohumeral stability (Ellenbecker, 1991; Ellenbecker, 1992; Elliot, Marsh, and Blanksby, 1986; Roetert, Ellenbecker, Chu and Bugg, 1997).

Beneka et al. (2002), in a classical study determined the effect of shoulder muscle training using exercises over a period of six weeks: one group followed multi-joint dynamic resistance training for the rotator cuff muscles and another one group of young healthy people trained following an isokinetic exercises program. The results showed statistically significant improvement in the internal and external rotator muscles strength after six weeks of training.

Alderink and Kuckl (1986), determined the isokinetic shoulder strength in twenty four high schools and college baseball pitchers ranging in age between fourteen to twenty one. No significant difference was found between torque output in the dominant and non-dominant internal rotators.

Codine et al, (1997), investigated shoulder internal rotation using an isokinetic device in baseball players, runners, tennis players and non-athletes, at angular velocities of $60 \%$ and $180 \%$. The results showed that the tennis players had greater torques produced by internal rotator muscles.

Mikesky et al. (1995), assessed bilateral isokinetic concentric muscular strength of the shoulder's internal rotator muscles in a twenty five collegiate baseball pitchers. They found no significant differences in concentric strength were observed between dominant and non-dominant arms of shoulder internal rotation.

Ivey et al., (1985), determined the shoulder strength in an isokinetic device in 18 males and 13 females athletes with an age range of 21 to 50 . No statistical differences were observed between the dominant and non-dominant hand. However, the mean torque values of the dominant side were higher.

Saccol et al. (2007), evaluated concentric isokinetic strength of shoulder rotators in 26 males and 14 females elite junior tennis players at 60 and $180 \%$ s. They showed in their study that the internal rotation strength on the dominant shoulder was greater in comparison to non-dominant hand.

Andrade et al. (2010), conducted a study to establish the isokinetic profile of shoulder rotator muscles strength in female handball players. They found that the internal rotation concentric strength in the dominant hand was greater than in the non-dominant hand. The authors suggested concentric strength exercises for internal rotators to improve their adaptations.

Brown et al. (1988), investigated the shoulder rotation in an isokinetic apparatus in professional baseball players. They found that shoulder internal rotator muscles of the dominant arm produced greater torque in comparison with the muscles of the non-dominant arm.

McMaster et al (1991), in their study determined the peak torques produced by the shoulder internal rotator muscles in elite water polo players. They found that there were significantly greater in the dominant arm than in the nondominant arm muscles.

Ellenbecker and Bleacher (1999), investigated the internal rotation strength in 38 females aged between 2545 years using the Cybex norm dynamometer. After analysis of their results, they found that the internal rotation shoulder strength was greater in dominant hand in comparison to non-dominant hand. The measurement of concentric and eccentric shoulder internal rotation, was done with the subjects in a seated position in $45^{\circ}$ of shoulder abduction in the scapular plane.

The second hypothesis of our study was that would be significant differences between years of experience and concentric/eccentric internal rotators strength at angular velocity of $120^{\circ} / \mathrm{sec}$ in dominant in dominant hand. Our results confirmed that boxers that had experience up to 10 years had better concentric and eccentric internal rotation strength in dominant shoulder, than the boxers who had boxing experience until 5 years. These adaptations at the 
same angular velocities, are mentioned in other sports in which the hand is used up to horizontal plane, lead to substantial gains in muscular strength (Ellenbecker and Roetert, 2002).

The third hypothesis of our study was that would be significant differences between years of experience and concentric and eccentric internal rotators strength at angular velocity of $180^{\circ} / \mathrm{sec}$ only in dominant hand. Our results confirmed that boxers that had experience up to 10 years had better concentric and eccentric internal rotation strength in dominant shoulder, than the boxers that had boxing experience until $5 \mathrm{y}$.

The next hypothesis was that would be significant differences between years of experience and concentric/eccentric internal rotators strength at $180^{\circ} / \mathrm{sec}$ in dominant hand. The analysis showed that boxers who had experience up to 10 years had better concentric/eccentric internal rotation strength in dominant shoulder, than the boxers who had boxing experience until 5 years. These adaptations are mentioned in other sports such as collegiate tennis (Chandler et al., 1992), elite junior and players (Koziris et al., 1991), in collegiate swimmers (McMaster, Long and Caiozzo, 1991), water polo players (McMaster, Long and Caiozzo, 1991), as well as wheelchair athletes (Burnham, et al., 1993).

\section{Reliability of isokinetic assessment of shoulder internal rotator strength:-}

For the assessment of concentric/eccentric shoulder internal rotation strength, we used for the present study, the seated position of $45^{\circ}$ of shoulder abduction in the scapular plane. This position seemed the most reliable for IR strength assessment, since its reliability has been studied in most methodologically high-quality studies (Codine et al., 2005; Davies, 1992; Dauty et al., 2003; Meeteren, Roebroeck and Stam, 2002; Plotnikoff and MacIntyre, 2002). The mentioned position has many advantages because is more comfortable, physiological and safe. More, it elicits optimal torque; and it showed good to excellent reliability for concentric/eccentric shoulder internal rotation strength (Davies, 1992; Edouard et al., 2011).

\section{Conclusions:-}

The present study showed that the training experience can increase the concentric power of shoulder internal rotation in the measurement angular velocities of 60,120 and $180 \%$ sec. These results confirm that the boxing experience plays an important role on the increase of internal shoulder rotators strength not only in the dominant hand, but in the non-dominant hand as well.However, it is unclear if bilateral symmetry in strength is adequate for long-term effective and injury-free sports performance in this group of boxing amateur athletes.

Further studies are necessary to elucidate the action of the shoulder internal rotators during a boxing punches, i.e., whether they act as primary propulsions or shoulder stabilizers. In addition, other factors such as shoulder flexors and extensors strength, punching and timing may be important determinants of glenohumeral stabilization and merit future study. More, future studies that incorporate a prospective design will be necessary to determine whether a point exists at which inadequate muscle strength is a risk factor for injury or negatively affects punching effectiveness without rotator cuff injuries.

\section{Acknowledgements:-}

The authors want to thank the study subjects for their willingness to participate. This study was conducted with the support of the University of Peloponnese.

\section{Conflict of Interest:-}

The authors reports no conflict of interest in the reporting of the present data.

\section{References:-}

1. Andrade, Mdos, S., Fleury, A.M., de Lira, C.A., Dubas, J.P. and da Silva, A.C. (2010): Profile of isokinetic eccentric-to-concentric strength ratios of shoulder rotator muscles in elite female team handball players. J. Sports Sci., 28(7):743-9.

2. Alderink, G.J., and Kuck, D.J (1986): Isokinetic shoulder strength of high school and college-aged pitchers. J. Orthop. Sports Phys. Ther., 7: 163-172.

3. Beneka, A., Malliou, P., Giannakopoulos, K., Kyrialanis, P., and Godolias, G.(2002): Different training modes for the rotator cuff muscle group. A comparative study. Isokinet. Exerc. Sci., 10:73-79.

4. Bompa, T., and Buzzichelli, C. (2015): Periodization Training for Sports, 3E: Human Kinetics. 
5. Brown, L.P., Niehues, S.L., Harrah, A., Yavorsky. P, and Hirshman, H.P. (1988): Upper extremity range of motion and isokinetic strength of the internal and external shoulder rotators in major league baseball players. Am. J. Sports Med., 16(6):577- 85.

6. Burnham, R.S., May, L., Nelson, E., Stead- ward R., Reid, D.C. (1993): Shoulder pain in wheelchair athletes: The role of muscle balance. Am. J. Sports Med., $21: 238-242$.

7. Chaabène, H., Tabben, M., Mkaouer, B., Franchini, E, et al. (2014): Amateur boxing: physical and physiological attributes. Sports Med., 34: 1-16.

8. Chandler, T.I., Kibler, W.B., Stracener, E.C., Ziegler, A.K., and Pace, B (1992): Shoulder strength, power, and endurance in college tennis players. Am. J. Sports Med., 20:455-458.

9. Codine, P., Bernard, P.L., Pocholle, M., Benaim, C., Brun, V. (1997): Influence of sports discipline on shoulder rotator cuff balance. Med. Sci. Sports Exerc., 29:1400-1405.

10. Codine, P., Bernard, P.L., Sablayrolles, P. and Herisson, C.(2005): Reproducibility of isokinetic shoulder testing. Isokinet. Exerc. Sci., 13:61-62.

11. Dauty, M., Delbrouck, C., and Huguet, D. (2003): Reproducibility of concentric and eccentric isokinetic strength of the shoulder rotators in normal subjects 40 to 55 years old. Isokinet. Exerc. Sci., 11:95-100.

12. Davies, G. (1992): A compendium of isokinetics in clinical usage and rehabilitation techniques. 4th ed. Onalaska, WI: S \& S.

13. Edouard, P., Samozino, P., Julia, M., GleizesCervera, S., et al. (2011): Reliability of isokinetic assessment of shoulder-rotator strength: A systematic review of the effect of position. J. Sport Rehabil., 20(3): 367-383.

14. Ellenbecker, T.S. and Roetert, E.P. (2002): Effects of a 4-month season on glenohumeral joint rotational strength and range of motion in female collegiate tennis players. J. Strength and Cond. Res., 16(1): 92-96.

15. Ellenbecker, T. S., and Davies, G. J. (2000): The application of isokinetics in testing and rehabilitation of the shoulder complex. J. Athl. Train., 35(3): 338-350.

16. Ellenbecker, T.S. (1991): A total arm strength isokinetic profile of highly skilled tennis players. Isok. Exerc. Sci., 1:9-21.

17. Ellenbecker, T. S., and Bleacher, J. (1999): A descriptive profile of bilateral glenohumeral joint internal and external rotation strength in uninjured females using the cybex NORM dynamometer. Phys. Ther., 79, S80.

18. Ellenbecker, T.S. (1992): Shoulder internal and external rotation strength and range of motion of highly skilled junior tennis players. Isokinet. Exerc. Sci., 2:1-8.

19. Elliot, B., Marsh, T. and Blanksby, B. (1986): A three-dimensional cinematographic analysis of the tennis serve. Int. J. Sport Biomech., 2:260-271.

20. Hellwig, E. V., and Perrin, D. H. (1991): A comparison of two positions for assessing shoulder rotator peak torque: the traditional frontal plane versus the plane of the scapula. Isok. Exer. Scie., 1(4): 202-206.

21. Hinton, R.Y. (1988): Isokinetic evaluation of shoulder rotational strength in high school baseball pitchers. Am. J. Sports Med., 16(3):274-279.

22. Ivey, F.M., Calhoun, J.H., and Rusche, K. (1985): Isokinetic testing of the shoulder strength. Normal values. Arch. Phys. Med. Rehabil., 66: 384-386.

23. Radcliffe, J.C. (1984): Farentinos RC. Plyometrics: Explosive power training. Boulder, CO: Exer Technics Publishers.

24. Koziris, L.P., Kraemer, W.J., Triplett, N.T., Fry, I., et al. (1991): Strength imbalances in women tennis players. Med. Sci. Sports Exerc. 23(Suppl): 253, (Abstract).

25. Koutedakis, Y. and Jamurtas, A.Z. (2014): The dancer as a performing athlete: physiological considerations. Sports Med., 34: 651-61.

26. McMaster, W.C., Long, S.C., and Caiozzo, V. (1992): Shoulder torque changes in the swimming athlete. Am. J. Sports Med., 20:323- 327.

27. McMaster, W.C., Long, S.C., and Caiozzo, V. (1991): isokinetic torque imbalances in the rotator cuff of the elite water polo player. Am. J. Sports Med., 19:72-75.

28. Meeteren, J., Roebroeck, M.E., and Stam, H.J. (2002): Test-retest reliability in isokinetic muscle strength measurements of the shoulder. J. Rehabil. Med., 34:91-95.

29. Mikesky, A.E., Eduards, J.E., Wiggelesworth, J.K. and Kunkel, S. (1995): Eccentric and concentric strength of the shoulder and arm musculature in collegiate baseball pitchers. Am. J. Sports Med., 23(5):638-42.

30. Pędzich, W., Mastalerz, A. and Sadowski, J. (2012): Estimation of muscle torque in various combat sports. Acta Bioeng. Biomech., 14: 107-112.

31. Plotnikoff, N.A. and MacIntyre, D.L. (2002): Test-retest reliability of glenohumeral internal and external rotator strength. Clin. J. Sport Med., 12:367-372. 
32. Ratamess, N. A. (2012): ACSM's foundations of strength training and conditioning: Wolters Kluwer Health/Lippincott Williams \& Wilkins.

33. Roetert, E.P., Ellenbecker, T.S., Chu, D.A. and Bugg, B.S. (1997): Tennis-specific shoulder and trunk strength training. Strength Cond. 19:31-39.

34. Saccol, M.F., da Silva, R.T., Gracitelli, G., Frota, C. et al. (2007): Concentric and eccentric isokinetic strength profile of shoulder rotators in elite junior tennis players XXV ISBS Symposium 2007, OuroPreto - Brazil, 60811.

35. Stergioulas, A. and Aggelidis, Ch. (2002): Kinesiology. O.E.D. Publ. Athens, Greece.

36. Stergioulas, A. (2005): Biology of exercise. Simmetria Publ. Athens, Greece.

37. Stergioulas, A. (1991): Sport injuries. Simmetria Publ. Athens, Greece.

38. Tillin. N.A. (2010): Neuromuscular performance of explosive power athletes versus untrained individuals. Med. Scie. Sports Exerc., 42(4): 781-790.

39. Wilhite, M. R, Cohen, E. R, and Wilhite, S. C. (1992): Reliability of concentric and eccentric measurements of quadriceps performance using the KIN-COM dynamometer: the effect of testing order for three different speeds. J.Orth.SportsPhys.Ther., 15(4): 175-182.

40. Wilk, K.E., Andrews, C.A., Arrigo, M.A., Kerns, M.A., et al., (1993): The strength characteristics of internal and external rotator muscles in professional baseball pitchers. Am. J. Sports Med., 21:61-66. 